Academic City University College - Accra Ghana

Society for Multidisciplinary \& Advanced Research Techniques (SMART) Africa

Tony Blair Institute for Global Change

FAIR Forward - Artificial Intelligence for All - Deutsche Gesellschaft für Internationale Zusammenarbeit (GIZ) GmbH

Accra Bespoke Multidisciplinary Innovations Conference (ABMIC)

\title{
Modelling Entrepreneurial Decision Making Process Using Fuzzy Inference Systems
}

\author{
Malasowe Bridget Ogheneovo \\ Department of Computer Science \\ Faculty of Computing \\ University of Delta \\ Agbor, Delta State, Nigeria \\ E-mail: malasowebrigit@gmail.com \\ Phone: +2348027539942
}

\author{
Emuobonuvie Andy \\ Department of Computer Science \\ Faculty of Computing \\ University of Delta \\ Agbor, Delta State, Nigeria \\ E-mail: aemuobonuvie@gmail.com \\ Phone:08033833867
}

Malasowe, B.O. \& Emuobonuvie, A. (2021): Modelling Entrepreneurial Decision Making Process Using Fuzzy Inference Systems. Proceedings of the Accra Bespoke Multidisciplinary Innovations Conference. University of Ghana/Academic City University College, Accra, Ghana. December 2021. Pp 99-110. www.isteams.net/ghanabespoke2021. DOI https://doi.org/ 10.22624/AIMS/ABMIC2021-V2-P8
} 


\title{
Modelling Entrepreneurial Decision Making Process Using Fuzzy Inference Systems
}

\author{
Malasowe Bridget Ogheneovo \& Emuobonuvie Andy
}

\begin{abstract}
The essence of Entrepreneurship is making decisions that are constantly required to evaluate alternatives and make decisions regarding a wide range of matters. Decision making involves a lot of uncertainty and risk which poses serious challenges for Entrepreneurs to joggle among them in other to take the best decision. Study have shown that focus has been mainly on the analysis of the characteristics of potential entrepreneurs and the firm-creation process leaving the critical incredient that will help in decision making. The increasing challenges and complexity of business environments are making business decisions and operations more difficult for entrepreneurs to predict the outcomes of these processes. Hence, this paper proposes a decision support model -Fuzzy Inference System- that could be adapted for various business decision processes. This system has the capability to handle decision making, by critically considering the degree of membership of all the risk involved in a given problem space.

The model uses the concept of fuzzy set theory to judiciously select the variables in a given problem space in an uncertain situations. From a real life practical point of view, this theory offers a natural approach to the resolution of multidimensional and complex problems when the available information is sparse and/or of poor quality. The fuzzy rule base sytem soften the adverse effects that a business may suffer from these uncertain factors.
\end{abstract}

Keywords: Fuzzy logic, Membership functions, Decision, Fuzzy Set, Entrepreneur

\section{INTRODUCTION}

In recent time, specific interest and research in entrepreneurship has captured the attention of both scholars and policy (Acs and Audretsch, 2003; Gürol and Atsan, 2006; Khefacha, Belkacem and Mansouri, 2014; Laviolette and Brunel, 2012; Norrman and Bager-Sjögren, 2010). Decision making is a very vital component of all businesses success. Decisions based on a foundation of knowledge and sound reasoning can lead the company into long-term prosperity; contrariwise, decisions made on the basis of unsound logic, emotionalism, or incomplete information can quickly put a business out of commission. Ultimately, what drives business success is the quality of decisions and their implementation. Good decisions mean good business.

The concept of decision making has a long history; choosing among alternatives has always been a part of life. But sustained research attention to business decision making has developed only in recent years. Contemporary advances in the field include progress in such elements of decision making as the problem context; the processes of problem finding, problem solving and legitimation; and procedural and technical aids. We are not able to use classical methods to solve some kind of problems given in sociology, economics, environment, engineering medical sciences and others, since these kinds of problems have their own uncertainties. 
Fuzzy set theory, which was firstly proposed by Zadeh in 1965, has become a very important tool to solve these kinds of problems and provides an appropriate framework for representing vague concepts by allowing partial membership. Fuzzy set theory has been studied by both mathematicians and computer scientists and many applications of fuzzy set theory have arisen over the years, such as fuzzy control systems, fuzzy automata, fuzzy logic, fuzzy topology, fuzzy decision making among others.

Being an entrepreneur means possessing outstanding decision rights to opinions or judgments on the future outcome of a business (Foss and Klein, 2007). We have also seen that the entrepreneur is an adventurer who needs to be able to deal with the risk that his or her judgments may be wrong (Casson, 2005). Dealing with risks requires adaptation, in the sense of experimenting with novel ideas and with completely new technologies to cope with complex problems and unanticipated opportunities (Bhidé, 2000). In this vain this paper proposes a nature based approach - fuzzy inference model approach for decision making that will be capable to handle the complexities involved in decision making by entrepreneurs.

\section{Theoretical Background of Fuzzy Logic and Fuzzy Decision Making System}

This paper is based on the principle of fuzzy logic a sub component of a nature inspired methodology - Soft Computing. This section will briefly dwell on principle of fuzzy set theory in order to contextualize this research paper.

As the complexity of a system increases, the utility of fuzzy logic as a modeling tool increases (Oderanti, 2010). Fuzzy logic (FL) allows approximate interpolation between input and output situations (Keshwani, Jones, Meyer and Brand, 2008). FL provides a conceptual framework that attempts to define a natural way of dealing with problems in which the source of imprecision is the absence of sharply defined criteria of class membership rather than the presence of random variables (Zadeh 1965). It is a problem solving technique that was introduced by Lotfi Zadeh in 1965 to deal with vague or imprecise problems (De Wilde 2004; DeWilde 2002; Dweiri and Kablan 2006; Kandel and Zhang 1998). FL is used to model human reasoning and knowledge that do not have well defined boundary.

Although fuzzy logic covers a wide range of theories and techniques, it is mainly based on four concepts: fuzzy sets, linguistic variables (Hajjaji and Rachid, 1995), possibility distributions (membership functions), and fuzzy if-then-rules (Dweiri and Kablan 2006). The values of a linguistic variable are both quantitatively described by a fuzzy set. Possibility distributions or membership functions are constraints on the value of a linguistic variable imposed by assigning it in a fuzzy set. Fuzzy if-then rules are knowledge representation schemes for describing a functional mapping between antecedents and consequents (Oderanti, 2010).

A Fuzzy Inference System (FIS) employs fuzzy if-then rules and can model the qualitative aspects of human knowledge and reasoning processes without employing precise quantitative analysis (Oderanti, 2010). FIS are generally understandable because the knowledge in these systems is contained in the form of fuzzy if-then rules containing membership functions (Anderson and Hall 1999). FIS can be teamed as computing with words. 


\subsection{Conceptual Problems in Entrepreneurhsip Decision}

In other to deal with the complex conceptual problems in entrepreneurship decision making, there is the need to model the system that will support decision making holisticallly. To achive this fuzzy logic has the capability in considering all possible contraints that affect decision making in an organisation. The emphasis is based on real world of actual entrepreneurial activity.

\section{REVIEW OF RELATED WORKS}

The concept of decision making has a long history; choosing among alternatives has always been a part of life. But sustained research attention to business decision making has developed only in recent years. Contemporary advances in the field include progress in such elements of decision making as the problem context; the processes of problem finding, problem solving, and legitimation; and procedural and technical aids.

All decisions are about problems, and problems shape context at three levels. The macrocontext draws attention to global issues (current exchange rates, for example), national concerns (the cultural orientations toward decision processes of different countries), and provincial and state laws and cultures within nations. The mesocontext attends to organizational cultures and structure. The microcontext addresses the immediate decision environment-the organization's employees, board, or office. Decision processes differ from company to company. But all companies need to take these three context levels into consideration when a decision needs to be made. An important difficulty in decision making is failure to act until one is too close to the decision point-when information and options are greatly limited. Organizations usually work in

a "reactive" mode. Problems are "found" only after the issue has begun to have a negative impact on the business.

Nevertheless, processes of environmental scanning and strategic planning are designed to perform problem reconnaissance to alert business people to problems that will need attention down the line. Proactivity can be a great strength in decision making, but it requires a decision intelligence process that is absent from many organizations. This is where Fuzzy Inference System comes into play. Moreover, problem identification is of limited use if the business is slow to heed or resolve the issue. Once a problem has been identified, information is needed about the exact nature of the problem and potential actions (decision(s)) that can be taken to rectify it.

Decision-Making in business has grown as a part of operations research, as concerned with designing computational and mathematical tools for supporting the subjective evaluation of performance criteria by decision-makers (Zavadskas, Turskis, and Kildienè, 2014). Several research work have been carried out to develop intelligent models to support decision making in an organisation (Zavadskas \& Turskis, 2010). As observed in analytical terms, the entrepreneur's notion and the organization of the firm are inseparable. Being an entrepreneur means possessing residual decision rights to opinions or judgments on the future outcome of a business (Foss et al., 2007). The researchers have also seen that the entrepreneur is an adventurer who needs to be able to deal with numerous risk(s) that his or her judgments may be wrong (Casson, 2005). Dealing with risks requires adaptation, in the sense of experimenting with novel ideas and with completely new technologies to cope with complex problems and unanticipated opportunities (Bhidé, 2000). 
Entrepreneurs did not perceive less risk but, instead, used more personal values to frame venture risks. They were also more confident in their ability to influence the development of the venture in the future. Simon, Houghton and Aquino in 2000 also found that entrepreneurs suffer from an illusion of control, i.e., they believed their skill will affect performance positively even in situations where it realistically cannot, or where it is evident that outcomes are highly dependent on chance. Similarly, Busenitz and Barney in 1997 posit that entrepreneurs are more overconfident and more likely to generalize from small random samples.

\subsection{Soft Computing in Decision making}

Furthermore several previous studies have employed different soft computing approach to support decision making in an organisation to solve problem(s) in a problem space in business growth and sustainability (Şengül et al, 2015). These are - inclusion-based TOPSIS method with interval-valued intuitionistic fuzzy sets for multiple criteria group decision making, Applied Software Computing (Roszkowska and Wachowicz, 2015). An improvement of quantitative strategic planning matrix using multiple criteria decision making and fuzzy numbers. Applied Soft Computing, production management (Rabbani, Zamani, Yazdani-Chamzini and Zavadskas, 2014). There is no unique and well-defined methodology that one could follow step-by-step from the beginning to the end of a decision aiding process. When dealing with objects that can only be described and compared using several characteristics, aggregation is a major issue: it aims at operating a synthesis of the usually contradictory, features of the objects, in view of achieving a goal such as choosing among the objects that has the highest degree of membership in a given problem space. (Bouyssou, Marchant, Pirlot, Tsoukias and Vincke, 2006). In all these research and methods applied, Fuzzy Inference System was not fully employed in that detailed fuzzy rules was not employed to extensively to cover all constraints in entrepreneur decision making. The aim of this paper is to propose a model that will judiciously select fuzzy rules in the entrepreneur problem space using Mamdani Fuzzy Inference Sytem approach that will be capable to support effective decisiom making in an organisation.

\subsection{Fuzzy Inference Systems in Decision making}

The intelligent behind FIS is to make use of rules that is generally known in a system to model the system that is driven by these rules. This gives rise to a complete system that can be used to model the complexities involved in decision making. This section will discuss a step by step approach on how to design a FIS for a given problem space (entrpreneur). The FIS is an intelligent system that is built to give correct outputs to known and unknown inputs. FIS are good at modling real life problems once the common characteristics or the general rules of the system is known.

\subsubsection{Computational Intelligence and Fuzzy Logic}

Computational Intelligence $(\mathrm{Cl})$ enables, through intelligent techniques some of them inspired by nature, the development of intelligent systems that imitate aspects of human behaviour, such as: learning, perception, reasoning, evolution and adaptation (Engelbrech, 2007). Some examples of Computational Intelligence techniques are: Artificial Neural Networks, biological neuron-inspired technique (Anagnostopoulos and Maglogiannis, 2006), (Aruna, Rajagopalan and Nandakishore 2011). Evolutionary Computation, inspired by biological evolution (Mohamed, Hegazy and Badr, 2011); Expert Systems, inspired by inference process (Anagnostopoulos , Anagnostopoulos, Vergados, Rouskas and Kormentzas, 2006); and Fuzzy Logic, inspired by language processing. The fuzzy systems theory is a formal approach that aims to address the modelling, representation, reasoning and the inaccurate information procedure as a troubleshooting strategy (Dubois and Prade, 1983). 
Introduced in 1965 (Zadeh, 1965), the fuzzy set theory is a tool to model the imprecision and ambiguity that arises in complex systems (Zadeh, 1965 and Zadeh 1979), and it was created from the combination of the concepts of classical logic and groupings, defining degrees of relevance (Lukasiewicz, 1970). Fuzzy logic is the principle concept of the proposed model in this paper.

A fuzzy set differs from a classic set to assign to each element a value in the unit interval $[0,1]$. Specifically, a fuzzy set is defined as a function A of a set $x$, called universe of discourse, to [0, 1]. The function $A$ is referred to as a membership function, and the value $A(x)$ represents the degree of relevance - or compatibility - of the element $x$ with the concept represented by all the fuzzy set. Thus, the fuzzy logic proposed by Zadeh (Zadeh, 1965, Zadeh, 1971) provides a mathematical model for the processing of inaccurate or vague information and concepts, intending to make computers carry out inferences as people. The fuzzy processing is generally composed of: Rules Base (provided by specialists or extracted from numerical data); Fuzzification Stage (activates the rules from a set of precise entries); Inference Stage (determines how rules are enabled); Defuzzification Stage (provides precise output, generating a fuzzy set of output).

\section{WHY FUZZY INFERENCE APPROACH}

The fuzzy logic method was preferred to current mathematical models due to its ability for modeling the obscurity in the related problem space, ability to work with lower cost and easy application, higher mechanical intelligence level, ability to solve new problems by using the experience of the model within the framework of the rules defined in the model, flexible structure, compatibility for solving the insufficiently defined problems, and use of intuitive methods instead of a specific algorithm (Yilmaz and Ayan (2013). The reasons for choosing fuzzy logic in contrast to other systems are grounded on the lack of a flexible structure of other systems, operation for accurate data and production of accurate results.

\subsection{Fuzzy Systems}

The fuzzy sets theory was initiated by Lofti A. Zadeh, in 1965. Fuzzy systems play a leading role in soft computing and this stems from the fact that human reasoning is not crisp and admits degrees. The notion central to fuzzy systems is that truth values (in fuzzy logic) or membership values (in fuzzy sets) are indicated by a value on the range [0,1], with 0 representing absolute falseness and 1 representing absolute truth. Fuzzy systems are based on fuzzy logic (FL). Fuzzy Logic is a form of many-valued logic or probabilistic logic; it deals with reasoning that is approximate rather than fixed and exact.

Fuzzy Logic incorporates a simple, rule-based IF X AND Y THEN Z approach to a solving control problem rather than attempting to model a system mathematically. FL provides a simple way to arrive at a definite conclusion based upon vague, ambiguous, imprecise, noisy or missing input information. Fuzzy logic has the advantage that the solution to the problem can be cast in terms that human operators can understand, so that their experience can be used in the design of the system. This makes it easier to mechanize tasks that are already successfully performed by humans using If -Then Rules (Fuzzy Logic). 


\subsection{Fuzzy Inference System}

A good Fuzzy Inference design needs to correctly map the inputs to the outputs, which is done by designing the correct rules in a gievn problem space. The major task is is to correctly and adequately identify the inputs and outputs. Rules are the driving factors of the fuzzy inference system and the degree of membership of the identified membership functions are also a strong contributing factor to the final result of the designed system.

One of the parameters in the design of a fuzzy inference system is the number of fuzzy sets associated to a linguistic term. Fuzzy inference system as a soft computing method mimics cognitive reasoning of the human mind based on linguistic terms for performing tasks in natural environments. Fuzzy Inference is the process of formulating the mapping from given input(s) to output(s) using fuzzy logic. This mapping provides a basis from which decisions can be made or patterns discerned. FIS has been applied successfuly in many applications in a wide variety of fields, such as Medicine, automatic control, data classification, decision analysis, expert systems, robotics, pattern recognition among others. A fuzzy inference system with crisp inputs and outputs implements a nonlinear mapping from its input space to output space.

This mapping is accomplished by a number of fuzzy if-then rules, each of which describes the local behavior of the mapping. In particular, the antecedent of a rule defines a fuzzy region in the input space, while the consequent specifies the output in the fuzzy region. Fuzzy logic models can be developed from expert knowledge or from process input-output data. In the first case, fuzzy models can be extracted from the expert knowledge of the process. The expert knowledge can be expressed in terms of linguistics, which is sometimes faulty and requires the model to be tuned. Therefore, identifying the processes is very important in the design which uses the help of expert knowledge in the domain area. This process requires defining the model input linguistic variables and the determination of the fuzzy model type.

In general, the main steps performed in the FIS are as follows:

- The fuzzification stage transforms each crisp input variable into a membership grade based on the membership functions defined in the problem space.

- The inference engine then conducts the fuzzy reasoning process by applying the appropriate fuzzy operators in order to obtain the fuzzy set to be accumulated based on their firing strenght in the output variable.

- The defuzzifier transforms the fuzzy output into a crisp output by applying a specific defuzzification method.

The two types of fuzzy inference methods most commonly used are the Mamdani method and the Sugeno method (Negnevitsky, 2001). The difference between these two fuzzy inference methodologies is the specification of the consequent part. In the Mamdani method (Mamdani \& Assilian, 1975), consequents are fuzzy sets, and the final crisp output of the Mamdani method is based on defuzzification of the overall fuzzy output using various types of defuzzification methods. This paper strongly recommends Mamdani approach because decision making in entrepreneur requires holistic consideration of many variables for final decision. The Mamdani fuzzy inference process includes four steps (Negnevitsky, 2001) (Naaz and Ranjit, 2011).

These are:

Step 1: Fuzzification -In fuzzification process the crisp input values are transformed into the grades of membership function (MF) for linguistic values of fuzzy sets. The membership function provides a grade for each linguistic value. 
Step 2: Rule Evaluation - After successfully defining the input and output variables, and the corresponding MFs, it is necessary to design the rule-base of the fuzzy knowledge-base. The rule-base of FIS design is composed of IF < antecedents > THEN < conclusion > rules. These rules are then transformed from an input to an output, based on MFs that inform the projected outcomes. The total number of rules is dependent on the total number of linguistic variables and MFs. In Mamdani, the AND operator is applied on each rule for rule evaluation.

Step 3: Aggregate output(s) - After evaluating all the rules, the rules need to be bundled together in a particular approach to make a decision. Aggregation method is used to bundle the output fuzzy set after the evaluation of the rules. In Mamdani, the OR operator is used to aggregate the output fuzzy sets. After aggregation, the final output is a single fuzzy set.

Step 4: Defuzzification - This stage comes up after all others of the fuzzy inference process. A crisp number is generated from the single output fuzzy set that is found from aggregating the rules in Step 3. Figure 1 shows the diagramatical presentation of an FIS.

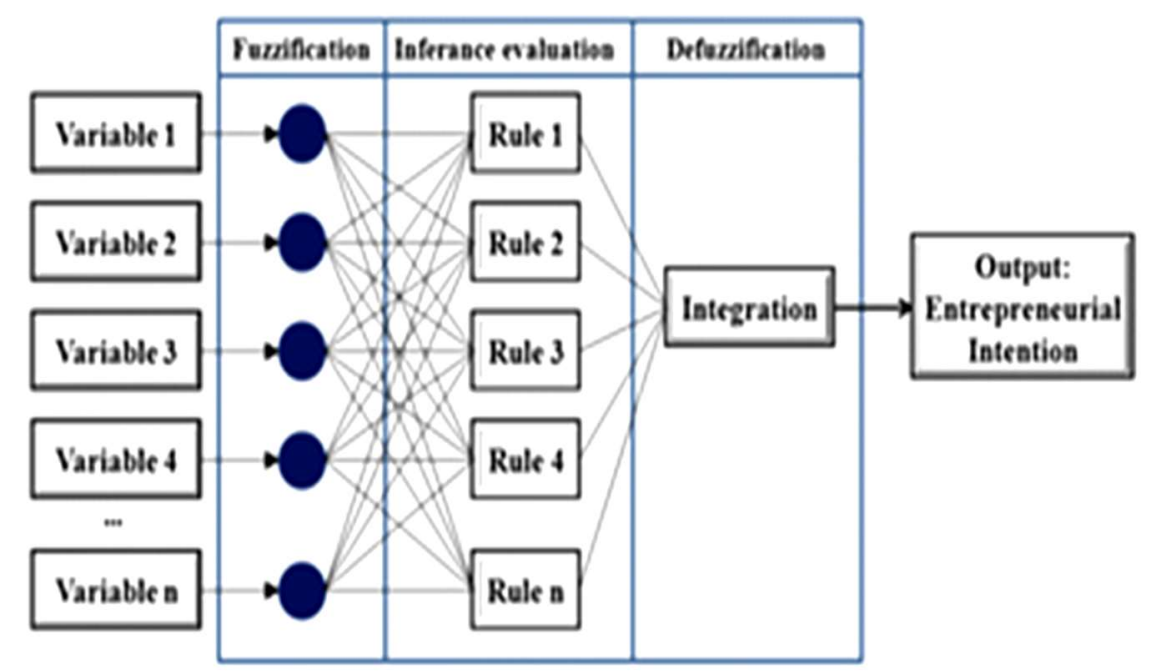

Figure 1 The Structure of Fuzzy Inference Systems for entrepreneurs

Source: Khefacha, Islem; Belkacem, Lotfi (2015)

\section{CONCLUSION}

In recent time alot of research have been on entrepreneurship in both academic research and practice. In applications and theories, different modelling techniques have been offered, a number of suitable approaches have been provided for modelling decision. Choosing a problem solution approach and a model is dependent upon the people that are involved in the process of decision making, oraganisation policies, available information and time among others. The most important advantage of FIS approach is its capability of addressing the problems that are marked by different conflicting interests considering their different degrees. 
This paper focused explicitly on the the need to explore the potentials of of softcomputing fuzzy logic in decision making. Fuzzy logic has the capability to handle holisticly the variables involved in decision making. It is quite possible that a better understanding of the factors that influence attitudes towards entrepreneurship and entrepreneurial intent could facilitate the successful development of these initiatives. This paper focused majorly on the main contraints that affeccts entrepreneural decision which will go a long way to alleviate the problems faced by entreprenuers in taking decisoin. 


\section{REFERENCES}

1. Acs, ZJ, \& Audretsch, DB. (2003). Introduction to the handbook of entrepreneurship research. In Handbook of entrepreneurship research (pp. 3-20). US: Springer.Google Scholar

2. Anderson DH, Hall L. IEEE International Conference on Systems, Man, and Cybernetics, 1999, vol 5. Tokyo: IEEE; 1999. Mr. fis: Mamdani rule style fuzzy inference system; pp. 238-243.

3. Bagočius, V., Zavadskas, E. K., \& Turskis, Z. (2014). Multi-person selection of the best wind turbine based on the multi-criteria integrated additive-multiplicative utility function. Journal of Civil Engineering and Management, 20, 590-

4. Bhidé, A. V. (2000). The origin and evolution of new businesses. New York: Oxford.

5. Bouyssou, D., Marchant, T., Pirlot, M., Tsoukiàs, A., \& Vincke, P. (2006). Evaluation and Decision Models with Multiple Criteria Stepping stones for the analyst. In. Boston, MA: Springer Science+Business Media Inc.

6. Brauers, W. K. M. \& Zavadskas, E. K. (2010). Project management by MULTIMOORA as an instrument for transition economies. Technological and Economic Development of Economy, 16, 5-24.10.3846/tede.2010.01

7. Busenitz, L. W., \& Barney, J. B. (1997). Differences between entrepreneurs and managers in large organizations: biases and heuristics in strategic decision-making. Journal of Business Venturing, 12(1), 9-30.

8. Casson, M. (2005). An entrepreneurial theory of the firm. In N. Foss, \& V. Mahnke. (Eds.). Competence, governance, and entrepreneurship: advances in economic strategy research (pp. 116-145). New York: Oxford University Press.

9. Casson, M. (2005). An entrepreneurial theory of the firm. In N. Foss, \& V. Mahnke. (Eds.). Competence, governance, and entrepreneurship: advances in economic strategy research (pp. 116-145). New York: Oxford University Press.

10. De Wilde P. Fuzzy utility and equilibria. IEEE Trans Syst, Man, Cybernetics-Part B: Cybernetics. 2004;34(4):1774-1785. doi: 10.1109/TSMCB.2004.829775.

11. DeWilde P. IEEE International Conference on Systems, Man, and Cybernetics. Piscataway: IEEE; 2002. Fuzzy constraints, choice, and utility; pp. MP1L4-MP1L4.

12. Dweiri FT, Kablan MM. Using fuzzy decision making for the evaluation of the project management internal efficiency. Decis Support Syst. 2006;42(2):712-726.

13. Foss, K., Foss, N. J., Klein, P. G., \& Klein, S. K. (2007). The entrepreneurial organization of heterogeneous capital. Journal of Management Studies, 44 (7), 1165-1186.

14. Foss, K., Foss, N. J., Klein, P. G., \& Klein, S. K. (2007). The entrepreneurial organization of heterogeneous capital. Journal of Management Studies, 44 (7), 1165-1186.

15. Gürol, Y, \& Atsan, N. (2006). Entrepreneurial characteristics amongst university students: Some insights for entrepreneurship education and training in Turkey. Education+ Training, 48(1), 25-38.Google Scholar

16. Hajjaji AE, Rachid A. Analytic formulation of linguistic rules for fuzzy controller. Fuzzy Sets Syst. 1995;73(2):219-225.

17. Khefacha, Islem; Belkacem, Lotfi (2015) : Modeling entrepreneurial decision-making process using concepts from fuzzy set theory, Journal of Global Entrepreneurship Research, ISSN 2251-7316, Springer, Heidelberg, Vol. 5, Iss. 13, pp. 1-21, http://dx.doi.org/10.1186/s40497-015-0031-x 
18. Kaklauskas, A., Zavadskas, E. K., Naimavicienè, J., Krutinis, M., Plakys, V., \& Venskus, D. (2010). Model for a complex analysis of intelligent built environment. Automation in Construction, 19, 326-340.10.1016/j.autcon.2009.12.006

19. Kanapeckiene, L., Kaklauskas, A., Zavadskas, E. K., \& Seniut, M. (2010). Integrated knowledge management model and system for construction projects. Engineering Applications of Artificial Intelligence, 23, 12001215.10.1016/j.engappai.2010.01.030

20. Kandel A, Zhang YQ. Fuzzy moves. Fuzzy Sets Syst. 1998;99(2):159-177

21. Keršuliene, V., Zavadskas, E. K., \& Turskis, Z. (2010). Selection of rational dispute resolution method by applying new step-wise weight assessment ratio analysis (Swara). Journal of Business Economics and Management, 11, 243258.10.3846/jbem.2010.12

22. Keshwani DR, Jones DD, Meyer GE, Brand RM (2008). Rule-based Mamdani-type fuzzy modeling of skin permeability. Appl Soft Comput.;8(1):285-294.

23. Khefacha, I, Belkacem, L, \& Mansouri, F. (2014). An Estimated Model of New Venture Creation: Theories and Determinants in Tunisia. Journal of Enterprising Culture, 22(02), 161-184.View ArticleGoogle Scholar

24. Kildienè, S., Zavadskas, E. K., \& Tamošaitienè, J. (2014). Complex assessment model for advanced technology deployment. Journal of Civil Engineering and Management, 20, 280-290.10.3846/13923730.2014.904813

25. Kracka, M., Brauers, W. K. M., \& Zavadskas, E. K. (2010, May 19-21). Buildings external walls and windows effective selection by applying multiple criteria method. In P. Vainiūnas, E. K. Zavadskas (Eds.), The 10th International Conference Modern Building Materials, Structures and Techniques: Selected papers (Vol. 1, pp. 436-441). Lithuania. Vilnius: Technika.

26. L.A. Zadeh, Fuzzy sets, Inform. Control 8 (1965) 338-353.

27. Laviolette, EM, Lefebvre, RM, \& Brunel, O. (2012). The impact of story bound entrepreneurial role models on self-efficacy and entrepreneurial intention. International Journal of Entrepreneurial Behaviour \& Research, 18(6), 720-742.View ArticleGoogle Scholar

28. Norrman, C, \& Bager-Sjögren, L. (2010). Entrepreneurship policy to support new innovative ventures: is it effective? International Small Business Journal, 28(6), 602619.View ArticleGoogle Scholar

29. Oderanti FO, De Wilde P. Dynamics of business games with management of fuzzy rules for decision making. Int J Prod Econ. 2010;128(1):96-109.

30. Oderanti FO. Fuzzy decision making system and the dynamics of business games. PhD thesis in Computer science, Heriot-Watt University, Edinburgh, United Kingdom, Computer Science Department. Edinburgh, UK: Heriot-Watt University; 2010.

31. Rabbani, A., Zamani, M., Yazdani-Chamzini, A., \& Zavadskas, E. K. (2014). Proposing a new integrated model based on sustainability balanced scorecard (SBSC) and MCDM approaches by using linguistic variables for the performance evaluation of oil producing companies. Expert Systems with Applications, 41, 73167327.10.1016/j.eswa.2014.05.023

32. Roszkowska, E. \& Wachowicz, T. (2015). Application of fuzzy TOPSIS to scoring the negotiation offers in ill-structured negotiation problems. European Journal of Operational Research, 242, 920-932.10.1016/j.ejor.2014.10.050

33. Şengül, Ü., Eren, M., Eslamian Shiraz, S., Gezder, V., \& Şengül, A. B. (2015). Fuzzy TOPSIS method for ranking renewable energy supply systems in Turkey. Renewable Energy, 75, 617-625. 
34. Simon, M., Houghton, S. M., \& Aquino, K. (2000). Cognitive biases, risk perception, and venture formation: how individuals decide to start companies. Journal of Business Venturing, 15(2), 113-134.

35. Turskis, Z. \& Zavadskas, E. K. (2010b). A novel method for multiple criteria analysis: Grey additive ratio assessment (ARAS-G) method. Informatica, 21, 597-610.

36. Zavadskas, E. K. \& Turskis, Z. (2010). A new additive ratio assessment (ARAS) method in multicriteria decision-making. Technological and Economic Development of Economy, 16(2), 159-172.10.3846/tede.2010.10

37. Zavadskas, E. K., Skibniewski, M. J., \& Antucheviciene, J. (2014). Performance analysis of Civil Engineering Journals based on the Web of Science ${ }^{\circledR}$ database. Archives of Civil and Mechanical Engineering, 14, 519-527.10.1016/j.acme.2014.05.008

38. Zavadskas, E. K., Turskis, Z., \& Kildienè, S. (2014). State of art surveys of overviews on MCDM/MADM methods. Technological and Economic Development of Economy, 20, 165-179.10.3846/20294913.2014.892037

39. Zavadskas, E. K., Turskis, Z., \& Vilutiene, T. (2010). Multiple criteria analysis of foundation instalment alternatives by applying Additive Ratio Assessment (ARAS) method. Archives of Civil and Mechanical Engineering, 10, 123-141.10.1016/S16449665(12)60141-1 